\title{
Peran Mahasiswa Sebagai Volunteer Dalam Meningkatkan Kualitas Literasi Di Desa 3t
}

\author{
Binur Yuni Artha Pardosi, ${ }^{1}$ \\ Lastri Mura Rizki Manurung ${ }^{2}$, Raras Firdarianti ${ }^{3}$
}

Pendidikan Masyarakat, Fakultas Ilmu Pendidikan, Universitas Negeri Medan Medan@Unimed.ac.id

Received: 04 Januari 2021; Revised: 26 Februari 2021; Accepted: 28 April 2021 DOI: http://dx.doi.org/10.37905/aksara.7.2.589-596.2021

\begin{abstract}
Abstrak
Penelitian ini memiliki fokus kajian mengenai Peran Volunteer dalam meningkatkan literasi untuk menumbuhkan budaya membaca dan meningkatkan kemampuan literasi masyarakat yang ada di desa 3T. Kajian ini bertujuan untuk mengetahui peranan volunteer salam pengabdiannya untuk meningkatkan literasi di desa 3T. Alasan dilakukan Kajian Literatur ini untuk memahami latar belakang para volunteer dalam meningkatkan literasi di desa 3T dan mengetahui peranan adanya volunteer dalam meningkatkan literasi tersebut di desa 3T. Pemahaman akan penggunaan bahasa Indonesia dalam masyarakat, minimnya pengetahuan dalam penggunaan alat komunikasi sebagai media pembelajaran, dan fasilitas sebagai oenunjang kegiatan atau proses belajar mengajar. Hal ini dilakukan untuk memahami latar belakang volunteer dan peranannya dalam meningkatkan budaya literasi. Metode deskriptif Pengumpulan data penelitian menggunakan tehnik wawancara, buku-buku, jurnal dan literatur lainnya yang digunakan dalam penelitian ini. Hasil dari kajian literatur ini adalah masih rendahnya penggunaan bahasa Indonesia yangditerapkan dalam masyarakat, karena masyarakat masih menggunakan bahasa daerahnya sendiri. Kemudian rendahnya pemahaman masyarakat mengenai penggunaan alat komunikasi seperti HP sebagai alat pembelajaran serta masih kurangnya fasilitas sebagai penunjang dalam keberhasilan proses belajar mengajar di desa 3T.
\end{abstract}

Kata kunci: volunteer, mahasiswa, tingkat literasi, pembelajaran.

Abstract: This research focuses on the study of the role of volunteers in improving literacy to foster a reading culture and improve the literacy skills of people in $3 T$ villages. This study aims to determine the role of volunteers in their service to improve literacy in $3 T$ villages. The reason for this Literature Review was to understand the backgrounds of volunteers in improving literacy in $3 T$ villages and to know the role of volunteers in increasing literacy in $3 T$ villages. Understanding of the use of Indonesian in society, lack of knowledge in the use 
of communication tools as a learning medium, and facilities to support teaching and learning activities or processes. This is done to understand the background of volunteers and their role in improving literacy culture. Descriptive method The research data collection used interview techniques, books, journals and other literature used in this study. The result of this literature review is the low use of Indonesian applied in society, because people still use their own local language. Then the community's low understanding of the use of communication tools such as cellphones as a learning tool and the lack of facilities to support the success of the teaching and learning process in $3 T$ villages.

Keywords: volunteers, students, literacy level, learning.

\section{PENDAHULUAN}

UNESCO menyebutkan Indonesiaurutan kedua dari bawah soal literasi dunia, artinya minat baca sangat rendah. Menurut data UNESCO, minat baca masyarakat Indonesia sangat memprihatinkan, hanya 0,001\%. Artinya, dari 1,000 orang Indonesia, cuma 1 orang yang rajin membaca. Riset berbeda bertajuk World's Most LiterateNations Ranked yang dilakukan oleh Central Connecticut State Univesity pada Maret 2016 lalu, Indonesia dinyatakan menduduki peringkat ke-60 dari 61 negara soal minat membaca, persis berada di bawah Thailand dan di atas Bostwana (61). Padahal,dari segi penilaian infrastuktur untuk mendukung membaca, peringkat Indonesia berada di atas negara-negara Eropa, 60 juta penduduk Indonesia memiliki gadget, atau urutan kelima dunia terbanyak kepemilikan gadget. Lembaga riset digital marketing Emarketer memperkirakan pada 2018 jumlah pengguna aktif smartphone di Indonesia lebih dari 100 juta orang. Dengan jumlah sebesar itu, Indonesia akan menjadi negara dengan pengguna aktif smartphone terbesar keempat di dunia setelah Cina, India, dan Amerika. Tunggul Harwanto, Pendiri Yayasan Rumah Literasi Indonesia mengatakan terdapatempat hal yang menyebabkan tingkat literasidi Indonesia masih rendah. Pertama, kurangnya dukungan atau keterlibatan keluarga dalam membangun budaya membaca di rumah sehingga anak-anak tidak terbiasa menjadikan buku sebagai rujukan untuk mendapatkan informasi. Kedua, akses buku yang berkualitas belum merata di sejumlah daerah. Anak-anak tidak memiliki kesempatan untuk mendapatkan referensi buku yang beragam.

Ketiga, budaya literasi tidak hanya tentang tata kelola buku di perpustakaan, dalam hal ini masyarakat belum sepenuhnya mengambil peran untuk meningkatkan ekosistem literasi yang produktif bagi anak-anak. Keempat, pemerintah dinilai belum mampu mengembangkan program literasi berbabasis gerakan. Bilapun ada selama ini hanya dianggap lebih ke arah seremonial yang cenderung mengarah ke sesuatu yang artificial. Kecerdasan dan pengetahuan di hasilkan oleh seberapa ilmu pengetahuan yang didapat, sedangkan ilmu pengetahuan di dapat dari informasi yang diperoleh dari lisan maupun tulisan. 
Semakin banyak penduduk suatu wilayah yang semangat mencari ilmu pengetahuan, maka akan semakin tinggi peradabannya. Budaya suatu bangsa biasanya berjalan seiring dengan budaya literasi, faktor kebudayaan dan peradaban dipengaruhi olehmembaca yang dihasilkan dari temuan temuan kaum cendekia yang diabadikan dalam tulisan yang menjadikan warisan literasi informasi yang sangat berguna bagi proses kehidupan sosial yang dinamis. Namun ironisnya jumlah terbitan buku di Indonesia tergolong rendah, tidak sampai 18.000 judul buku per tahun. Jumlah ini lebih rendah dibandingkan Jepang yang mencapai 40.000 judul buku per tahun. (Sumber: Majalah Oase Edisi April 2014). Sebagai warga Indonesia, tentu hal ini sangat menyedihkan bagi kita.Secara sederhana, literasi dapat diartikan sebagai sebuah kemampuan membaca dan menulis. Kita mengenalnya dengan melek aksara atau keberaksaraan. Namun sekarang ini literasi memiliki arti luas, sehingga keberaksaraan bukan lagi bermakna tunggal melainkan mengandungberagam arti (multi literacies). Ada bermaca macam keberaksaraan atau literasi, misalnya literasi komputer (computer literacy), literasi media (media literacy), literasi teknologi (technology literacy), literasi ekonomi (economy literacy), literasi informasi (information literacy), bahkan adaliterasi moral (moral literacy). Jadi, keberaksaraan atau literasi dapat diartikanmelek teknologi, melek informasi, berpikir kritis, peka terhadap lingkungan, bahkan juga peka terhadap politik.

Definisi baru dari literasi menunjukkan paradigma baru dalam upaya memaknai literasi dan pembelajaran nya. Kini ungkapan literasi memiliki banyak variasi, seperti Literasi media, literasi komputer, literasi sains, literasi sekolah, dan lain sebagainya. Hakikat ber-literasi secara kritis dalam masyarakat demokratis diringkas dalam lima verbal: memahami, melibati, menggunakan, menganalisis, danmentransformasi teks. Kesemuanya merujukpada kompetensi atau kemampuan yang lebih dari sekedar kemampuan membaca dan menulis.

National Institute for Literacy, mendefinisikan Literasi sebagai "kemampuan individu untuk membaca, menulis, berbicara, menghitung dan memecahkan masalah pada tingkat keahlian yang diperlukan dalam pekerjaan, keluarga dan masyarakat.” Definisi ini memaknai Literasi dari perspektif yang lebih kontekstual. Dari definisi ini terkandung makna bahwa definisi Literasi tergantung pada keterampilan yang dibutuhkan dalam lingkungan tertentu.

\section{METODOLOGI PENELITIAN}

Penelitian ini menggunakan pendekatakan peneltian kualitatif. Berdasarkan Modul Rancangan Penelitian (2019) yang diterbitkan Ristekdikti, penelitian kualitatif bisa dipahami sebagai prosedur riset yang memanfaatkan data deskriptif, berupa kata-kata tertulis atau lisan dari orang-orangdan pelaku yang dapat diamati. Penelitian kualitatif dilakukan untuk menjelaskan dan menganalisis fenomena, peristiwa, dinamika sosial, sikap kepercayaan, dan 
persepsi seseorang atau kelompok terhadap sesuatu. Subjek dari penelitiana ini adalah mahasiswa yang mengabdikan dirinya sebagai volunteer.

Peneliti memilih metode kualititaf karena menginginkan hasil penelitian yang mendalam dan menyeluruh atas fenomena yang akan diteliti. Pada pendekatan kualitatif ini, peneliti mengumpulkan informasisebanyak mungkin dari para partisipan, lalumembentuk informasi ini menjadi kategon- kategori atau tema-tema tertentu (Creswell, 2012:96). Tema ini kemudian dikembangkan menjadi pola-pola, teori-teori atau generalisasi-generalisasi untuk nantinya diperbandingkan dengan pengalaman-pengalamn pribadi atau dengan literaturliteratur yang ada.

\section{HASIL DAN PEMBAHASAN}

\section{HASIL}

Indonesia kini sedang mencanangkan gerakan untuk meningkatkan Literasi khususnya daerah 3T yang sulit untuk dijangkau oleh pemerintah maka dari itubanyak civitas akademik baik dari perguruan tinggi hingga organisasi memberikan kesempatan kepada Mahasiswa untukmengabdikan dirinya untuk kemajuan Negeri ini khususnya dalam bidang Pendidikan. Tidakmain-main demi meningkatkan kualitas Literasi di Indonesia ada beberapa lembaga yang mengadakan seleksi Nasional demi mencari mahasiswa yang bersedia menjadi Volunteer, benefit yang didapatkan tidak hanya berupangalaman namun juga uang saku dari kegiatan tersebut. Tidak sedikit juga organisasi yangmengadakan kegiatan pengabdian yangmelibatkan mahasiswa sebagai volunteer di dalamnya. Banyaknya peminat mahasiswa untuk menjadi volunteer juga membuat penyelenggara mengadakan seleksi mengenai kompetensi yang dimiliki mahasiswa.

Peranan mahasiswa sebagai volunteer telah banyak memberikan kemajuan dalam hal berliterasi seperi:

1. Penggunaan Bahasa Indonesia yang saat ini sangat jarang digunakan untuk di Daerah 3T yang lebihdominan menggunakan Bahasa Daerah pada saat proses pembelajaran berlangsung disekolah yang dilakukan baik oleh Guru maupun Murid. Pemahaman mengenai penggunaan Bahasa Indonesia di daerah-daerah 3T memang masih sangat rendah hal ini dibuktikan dengan cara mereka menggunakan Bahasa Indonesia dengan pelafalan yang tidak tepat sampai tidak tau dan tidak mengerti arti beberapa kata dalam Bahasa Indonesia.

2. Penggunaan alat komukasielektronik seperti Handphone yangkini telah merambah ke daerah terpencil sekalipun walaupun aksesinternet tidak mendukung namunkita tidak bisa memungkiri bahwa kemajuan zaman sudah bersifatuniversal. Kurangnya literasi membuat anak-anak khususnya yangtinggal di daerah 3T menggunakan HP nya hanya untuk 
mengikuti trendpadahal HP sendiri dapat membantu mereka khususnya dalam kegiatan belajar mengajar.

3. Kegiatan yang biasanya dilakukan sebagai volunteer adalah memfasilitasi anak-anak di tempat pengabdian dengan program-program yang sebelumnya telah dirancang contohnya sepertimembuat Taman Baca yang sangat membantu peningkatan Literasi anak-anak dari banyak membaca.Karna biasanya akses untuk anak- anak mendapatkan buku bacaan itu hanya terdapat disekolah maka dari itu upaya yang dilakukan volunteer membuat falitisa membaca yang dapat dilakukan ditemapa mereka biasanya menghabiskan banyak waktu seperti ditempat bermain.

Rendahnya akses masyarakat terhadap bacaan terkonfirmasi dari hasil survei Badan Pusat Statistik (BPS) mengenai persentasependuduk di atas 10 tahun yang mengaksesmedia, terutama apabila membandingkan antara meningkatnya akses masyarakat terhadap televisi yang berbanding terbalik dengan akses masyarakat terhadap surat kabar/majalah. Persentase penduduk Indonesiayang menonton televisi pada 2009 - 2015 mencapai lebih dari 90 persen, sementara penduduk yang mendengarkan radio dan membaca surat kabar cenderung menurun. Pada 2009, pendengar radio sekitar 23,50persen menjadi 7,5 persen di tahun 2015.Sedangkan pembaca surat kabar sekitar 18,94 persen di tahun 2009, menjadi 13,11 persen di tahun 2015 (Statistik Sosial Budaya 2015).

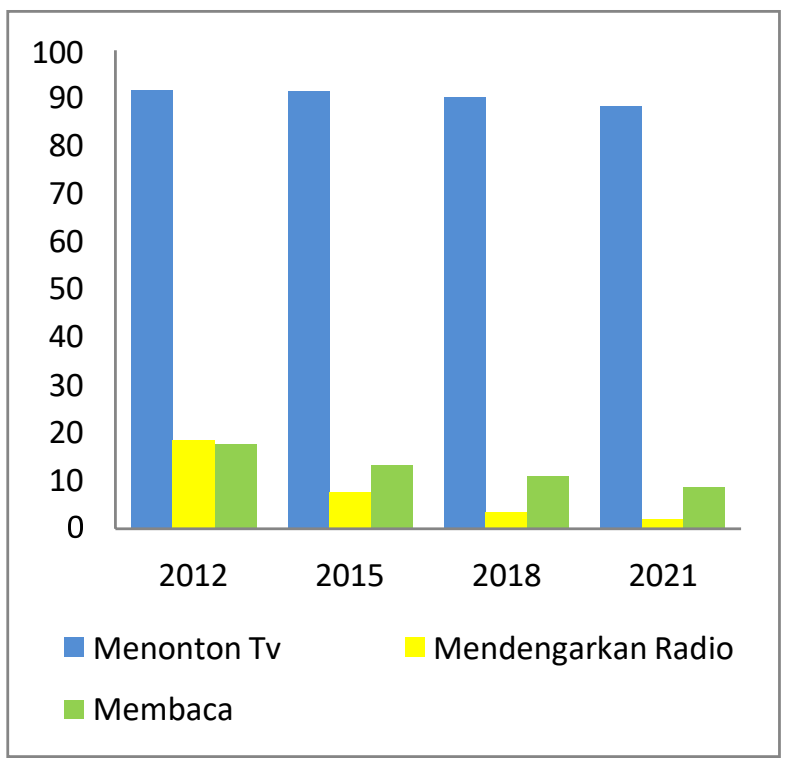

Grafik 1.1. Persentase Penduduk 10 Tahun keAtas yang Mengakses Media

Tiga parameter di atas, yaitu (1) minimnya akses di sekolah, (2) minimnya akses di masyarakat, serta (3) rendahnyaperilaku membaca dibandingkan dengan mengakses media lainnya, menunjukkan 
kendala yang melatari persoalan literasi masyarakat khususnya anak-anak Indonesia yang sedang dihadapi oleh program- program volunteer. Upaya untuk meningkatkan literasi tidak dapat dilakukan tanpa memahami peta persoalanliterasitersebut. Di samping itu, tanpa memahami peta persoalanitu, maka capaian hasil program volunteer juga sulit diukur. Sebagai contoh, buku Panduan Gerakan Literasi Nasional 2017 dan Peta Jalan Gerakan Literasi Nasional 2017 yang diterbitkan oleh Kemdikbudtidak menyajikan telaah mengenai kondisi, jumlah, dan persebaranperpustakaan sekolah maupun perpustakaan umum di seluruhIndonesia. Padahal data mengenai jumlah,kondisi, dan persebaran perpustakaan sekolah dan perpustakaan umum merupakansalah satu indikator tersedianya akses terhadap bahan-bahan literasi bagi siswa dan masyarakat. Tersedianya akses merupakan salah satu faktor penting yang memungkinkan aktivitas literasi dapat dilakukan (Miller dan McKenna, 2016).

\section{PEMBAHASAN}

Kontribusi yang diberikan mahasiswa untuk negeri berupa peningkatan literasi bertujuan untuk membantu program Gerakan Literasi Nasional (GLN) mengingat luasnya spektrum literasi sebagaimana disebutkan di atas, istilah literasi dalam Indeks Alibaca hanya mencakup literasi membaca. Term literasi dalam Indeks Alibaca dibatasi hanya pada aktivitas membaca teks sebagaimana pengertian 'peristiwa literasi', yaitu peristiwa atau kegiatan subjek dalam menggunakan teks atau bahan bacaan (Barton dan Hamilton, 2000; Heath dan Street, 2008). Hasil indeks ini dengan demikian hanya menyajikan gambaran mengenai aktivitas literasi membaca masyarakat di suatu wilayah, bukan literasi dalam makna yang lain. Batasan cakupan ini penting disebutkan mengingat dua hal. Pertama, upaya menyusun indeks literasi yangmencakup enamliterasi dasar sulit dilakukan mengingat luas dan beragamnya indikator di masing-masing bidang literasi. Dengan membatasicakupan, maka indikator danpenafsirannya jadi lebih fokus dan terarah. Kedua, hasil indeks yang lebih spesifik dapat menjadi tolok ukur bagi para pemangku kepentingan guna mendorong aktivitas literasi membaca di masyarakat.

Pengajaran bahasa Indonesia yang berfungsi sebagai bahasa nasional dan bahasa negara, memiliki dua peran penting dalam kurikulum yaitu: 1) meningkatkan penguasaan berbahasa, dan 2) membentuk kompetensi literasi. Yang pertama, melalui pembelajaran dapat ditingkatkan kemampuan siswa dalam menyimak, berbicara, membaca, dan menulis. Yang kedua, meningkatkan penguasaanketerampilan membaca dan menulis (tanpa menafikan keterampilan menyimak danberbicara). Kompetensi membaca dan menulis yang diperoleh siswa dari belajar bahasaIndonesia selain berguna dalam lingkuppelajaran bahasa juga dibutuhkan untukmenguasai bermacam informasi yang terdapat dalam mata pelajaran lain. 
Berbicara tentang pembelajaran literasi, Axford (2009:9) mengatakan bahwasalah satu tujuan pembelajaran literasi adalah membantu siswa memahami dan menemukan strategi yang efektif dalam hal kemampuan membaca dan menulis, termasuk di dalamnya kemampuan menginterpretasi makna teks yang kompleks dalam struktur tata bahasa dan sintaksis. Maka kemampuan meningkatkan kualitas literasi di Daerah 3T khususnya menggunakan Bahasa Indonesia pada saatpembelajaran sesuai dengan tujuan dariliterasi. Selain liteasi bahasa,dalam pengabdian mahasiswa juga mengajarkan literasi digital.Kegiatan literasi ini biasanyamemberikan pemahaman seperti bagaimana memfilter berita hoax,mencermati alamatsitus,memakai teknologi yang tersedia baik hardware maupun software yang tentunyaberguna untuk meningkatkan berbagai aspekyang ada di masyarakat objek pengabdian.

Sebagai impact nyata dari pengabdian mahasiswa biasanya memberikan bukti nyata berupa produk atau program yang bersifat sustainable.Program yang biasa diberikan adalah Taman Baca Masyarkat yang kemudian program ini juga memilikikegaitan pembangunan dan pemberdayaanberbasis pengajaran dengan memperhatikan literasi bahasa dan juga literasi digital.Taman Baca Masyarakat (TBM) bukan wadah yang hanya menyediakanbuku-buku untuk dibaca oleh masyrakat tetapi TBM adalah pusat kegiatan inofativ.Sehingga diharapkan melalui program tersebut akan tercipta masyarakat yang melek akan literasi sesuai dengan kebutuhan.

\section{PENUTUP}

Berdasarkan hasil penelitian yang diperoleh dari pengumpulan data dan informasi dari sumber-sumber yang didapat, maka kesimpulannya adalah (1) Rendahnya penggunaan bahasa Indonesia < masyarakat lebih banyak menggunakan bahasadaerahnya sendiri yang mengakibatkan bahasa Nasional tidak berkembang dengan baik sehingga di tumbuhkanlah kesadaran masyarakat

terhadap pentingnyapenggunaan bahasa Indonesia di desa 3T; (2) Masih kurangnya pemahaman masyarakat terhadap penggunaan teknologi digital berupa alat komunikasi yaitu Handphone sebagai alat atau media pembelajaran, karena masyarakat hanya memahami bahwasanya handphone hanya sebatas mengikuti Trend kekinian padahal mereka tidak mengetahui bahwasanya Handphone juga bisa dijadikan sebagai alat pembelajaran agar masyarakat juga tidak ketinggalan ilmu dan informasi mengenai literasi; (3) Kurangnya fasilitas penunjangyang akan digunakan dalam meningkatkan literasi pada masyarakat 3T, sepetiTBM,Buku bacaan dan lainnya, dalam pengabdian dan penelitian ini, volunteer menerapkan dan mengajarkan kepada masyarakat mengenai literasi bahasa dan literasi digital. 


\section{Saran}

Berdasarkan hasil pembahasan dan simpulan yang diperoleh, maka diajukan beberapa saran bagi volunteer (relawan) dan Pemerintahan sebagai berikut: (1) pengadaan koleksi bahan pustaka lebih memperhatikan bahan koleksi yang lebih banyak dibutuhkan oleh masyarakat; (2) volunteer harus lebihmenyediakan sarana dan pra sarana yang memadai,seperti Taman Baca Masyarakat agar membantu masyarakat dalam peningkatan literasi; (3) Sosialisasi terhadap fasilitaspenunjang seperti Taman Bacaan Masyarakat baik melalui media massa maupun media sosial terkhususnya untuk masyarakat desa 3T agar masyarakat dapat mengetahui dan mengunakan fasilitas tersebut dengan baik; (4) pihak pemerintah membuat program pengabdian di desa $3 \mathrm{~T}$ agar dapat memunculkan volunteer-volunteer yang baru, berkreasi dan berinovasi untuk membantudalam meningkatkan literasi di desa 3T; (5)perlunya sosialisasi pentingnya membaca akanmembantu membaca bagi masyarakat.

\section{DAFTAR PUSTAKA}

Indragiri, C. A., Suprihanto, J., \& Hamid, M. (2019). Upaya Peningkatan LiterasiBaca Tulis Melalui PembiasaanMenulis Jurnal Harian AnakKelas 4 Sdn 1 Kretek (Doctoral

dissertation, STIE Widya Wiwaha). Mudana, I. G. A. M. G. (2020). Membangkitkan Budaya Literasi Melalui Pendekatan Think Pair Share Berbasis Saintifik Dalam Pembelajaran Bahasa Indonesia Menuju Siswa Berkarakter. PINTU: Jurnal Penjaminan Mutu, 1(1).

Idawati, G. (2011). IbM Tutor Warga Belajar Buta Aksara di Kecamatan Lamuru Kabupaten Bone (Doctoral dissertation, Lembaga Penelitian Universitas Negeri Makassar).

Aliyudin, R. S., \& Ahmad, E. F. (2020). Analisis Pengembanagan Kantor Pelayanan, Penyuluhan, Dan Konsultasi Perpajakan (Kp2kp) Menjadi Kantor Pelayanan PajakMikro Dalam Melakukan Intensifikasi Pajak. JAKSI, 1(2), 13-23.

Irawan, D. E. (2018). Kajian Pendidikan Tinggi IDRI untuk DPR RI dan Ristek Dikti2018.

Permatasari, A. (2015). Membangun kualitas bangsa dengan budaya literasi.

Susanti, D., \& Santi, S. (2019). Pemanfaatan Taman Bacaan Masyarakat (Tbm) Dalam Meningkatkan Minat Baca

Remaja (Studi Kasus di TBM Gunung Ilmu). Comm-Edu (Community EducationJournal), 2(3), 220-226 